\title{
Industrial Applications of Electron Probe Microanalysis (EPMA)
}

\author{
Goresh, S.L.*
}

*Analytics and Materials Characterization, BASF Catalyst Division, BASF Corporation, 25 Middlesex/Essex Tpk, Iselin, NJ, 08830

Electron beam analysis has become a critical tool used in materials analysis. Initially, EPMA was used in the field of geology for mineral analysis. However, in the field of catalysis, where multielement compositions in many of the formulations result in significant spectral overlaps, the better spectral resolution of the Wavelength Dispersive Spectroscopy (WDS) detectors compared to SDD Energy Dispersive Spectroscopy (EDS) make the EMP a more appropriate tool when detection of trace elements in multi-elemental materials and the accuracy of the quantification are imperative. Spectra of rare earths obtained by WDS and SDD EDS are shown in Fig. 1 and Fig. 2. In addition, the higher cost of precious metals has driven the research in catalyst development to products with lower amounts of these elements. The ability of WDS to detect down to 100 or less ppm concentrations with $1 \%$ error compared to detectibility limits of only $1000 \mathrm{ppm}$ and $25 \%$ to $50 \%$ error for standardless EDS analysis and $500 \mathrm{ppm}$ with 5\% error for calibrated EDS also enhances its use in the field of catalysis R\&D. [1]

BASF has used EPMA for the past 30 years to help guide the development of new catalysts as well as resolve manufacturing and customer related issues. Chemical associations observed by EPMA are often used to pursue further investigation.

One dimensional, line profile data is routinely used to assist catalyst development to give spatial quantitative data of multilayer catalyst washcoats. EPMA data is also used to chart compositional differences in various catalysts, as well as to monitor process changes on catalyst architecture, and to look for probable causes of deactivation or failure. Distribution of precious metals and support materials is critical for achieving maximum conversion of effluent gases in environmental catalysts.

Two dimensional qualitative and quantitative x-ray mapping has been applied to help understand uniformity issues in production and process design. Line profile data while much quicker to collect and more accurate than quantitative mapping, can cause many features to escape detection due to the limited scope of the analysis.

References

[1] Paula Horny, Microsc. Microanal. 16 (2010) 821-830

[2] The assistance of Adam Ross in data collection and processing is gratefully acknowledged.

[3] The author wishes to thank Dr. Fabian Krueger, Product Technology Manager CCP/KC, BASF Corp, De Meern, Netherlands; Dr. Tian Luo, Research Chemist GCC/ET, BASF Corp, Iselin, NJ; Dr. Junmei Wei, Research Chemist, GCC/ET, BASF Corp, Iselin, NJ; Mr. Gary Gramiccioni, R\&D Group Leader, Advanced Process Development, BASF Corp, Huntsville, AL for supplying the catalysts whose data are presented. 


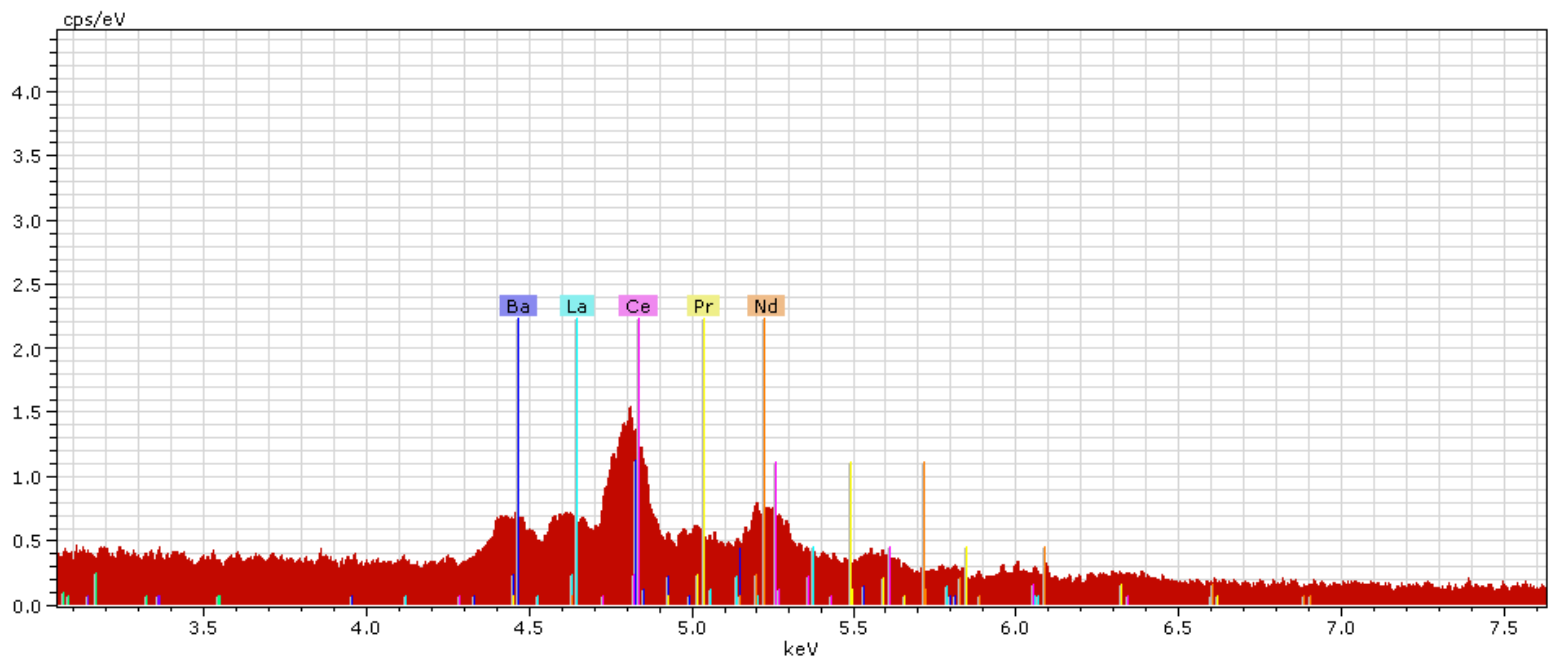

Fig 1. EDS spectra of Rare Earth Elements using Rontec (Bruker) SDD.
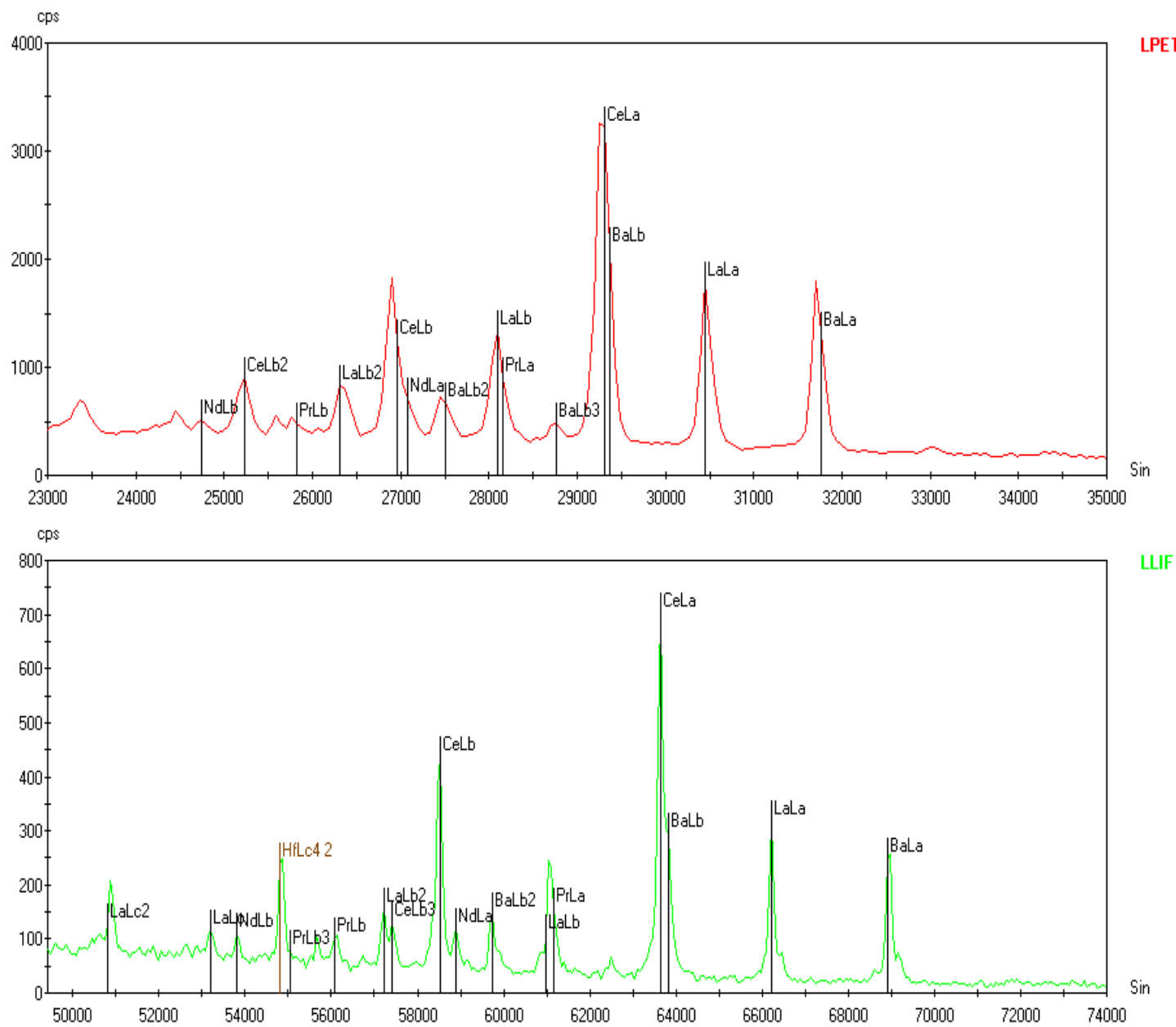

Fig 2. WDS spectra of Rare Earth Elements using Cameca SX-100 EMP 